\title{
Optimization of S:Sn precursor molar concentration on the physical properties of spray deposited single phase $\mathrm{Sn}_{2} \mathrm{~S}_{3}$ thin films
}

\author{
J. SRivind, V.S. NAGAREThinam, A.R. BALU* \\ PG and Research Department of Physics, AVVM Sri Pushpam College, Poondi-613 503, Tamilnadu, India
}

\begin{abstract}
Nanoneedle structured $\mathrm{Sn}_{2} \mathrm{~S}_{3}$ thin films were prepared by spray pyrolysis technique from aqueous solutions of tin (II) chloride and thiourea, keeping the molar concentrations of $\mathrm{S}: \mathrm{Sn}=0.01: 0.01,0.02: 0.02,0.03: 0.03$ and 0.04:0.04 in the starting solutions. XRD studies reveal that all the films exhibit orthorhombic crystal structure with a preferential orientation along the $\left[\begin{array}{lll}2 & 1 & 1\end{array}\right]$ direction. The peak intensity of the $\left(\begin{array}{lll}2 & 1 & 1\end{array}\right)$ plane is found to be maximum for the film coated with 0.02:0.02 S:Sn molar concentration which confirms the improved crystalline nature of this film. SEM images depict that the film coated with S:Sn molar concentration 0.02:0.02 exhibit needle shaped grains. The optical band gap exhibits red shift from $2.12 \mathrm{eV}$ to $2.02 \mathrm{eV}$ with an increase in $\mathrm{S}: \mathrm{Sn}$ precursor molar concentration. Electrical studies show that the films having S:Sn molar concentrations 0.01:0.01 and 0.02:0.02 exhibit minimum resistivity values of 0.238 and $0.359 \Omega \cdot \mathrm{cm}$, respectively.
\end{abstract}

Keywords: XRD; scanning electron microscopy; optical band gap; thin films

(C) Wroclaw University of Technology.

\section{Introduction}

Photovoltaic (PV) technology provides a significant fraction of the world's energy demands, so photovoltaic devices must be composed of cheap and abundant materials. Tin based chalcogenide materials appear to be very cheap and abundant in nature. Tin forms a variety of sulfides, such as $\mathrm{SnS}, \mathrm{SnS}_{2}, \mathrm{Sn}_{2} \mathrm{~S}_{3}, \mathrm{Sn}_{3} \mathrm{~S}_{4}, \mathrm{Sn}_{4} \mathrm{~S}_{5}$ and numerous polysulfide anions. Among these sulfides, $\mathrm{SnS}_{2}$ and $\mathrm{SnS}$ exhibit layered structures while $\mathrm{Sn}_{2} \mathrm{~S}_{3}$ exhibits ribbon like structure [1]. $\mathrm{Sn}_{2} \mathrm{~S}_{3}$ normally crystallizes in orthorhombic phase consisting of infinite double rutile strings of $\mathrm{Sn}^{\mathrm{IV}} \mathrm{S}_{6}$ octahedra parallel to the c-axis, with the $\mathrm{Sn}$ (II) atoms being attached laterally [2]. $\mathrm{Sn}_{2} \mathrm{~S}_{3}$ is a direct forbidden semiconductor which has a band gap between $0.95 \mathrm{eV}$ and $2.2 \mathrm{eV}$ [3]. The high anisotropic conductivity possessed by $\mathrm{Sn}_{2} \mathrm{~S}_{3}$ make it suitable for building photovoltaic $\mathrm{p}-\mathrm{n}$ or $\mathrm{p}$-i-n structures [4].

*E-mail: arbalu757@gmail.com
$\mathrm{Sn}_{2} \mathrm{~S}_{3}$ has been found to be suitable for preparing heterojunctions applied in photoconductive sensor applications. $\mathrm{Sn}_{2} \mathrm{~S}_{3}$ films have been prepared by several techniques such as spray pyrolysis [5], plasma-enhanced chemical vapor deposition [6], electro deposition [7], sol-gel dip coating [8], molecular beam epitaxy [9] and SILAR [10]. Among these deposition techniques, spray pyrolysis seems to be one of the most attractive techniques for fabricating thin films due to its simplicity, cheapness and capability to produce large area coatings. In addition, spray pyrolysis technique requires neither high quality substrates nor vacuum at any stage. There are earlier reports on the fabrication of $\mathrm{Sn}_{2} \mathrm{~S}_{3}$ films by spray pyrolysis technique $[11,12]$. However, none of the above studies investigated the effect of precursor molar concentration on the structural, morphological, optical and electrical properties of $\mathrm{Sn}_{2} \mathrm{~S}_{3}$ thin films. Therefore, in this study, $\mathrm{Sn}_{2} \mathrm{~S}_{3}$ thin films with different $\mathrm{S}: \mathrm{Sn}$ molar concentrations were deposited by spray pyrolysis technique and the effects of precursor molar concentration on the structural, 
morphological, optical and electrical properties of the films were studied.

\section{Experimental}

$\mathrm{Sn}_{2} \mathrm{~S}_{3}$ films were fabricated by spray pyrolysis technique from aqueous solutions of $\mathrm{SnCl}_{2} \cdot 2 \mathrm{H}_{2} \mathrm{O}$ (source for tin ions) and $\mathrm{CS}\left(\mathrm{NH}_{2}\right)_{2}$ (source for sulfur ions). The molar concentrations of $\mathrm{S}: \mathrm{Sn}$ in the precursor solutions were kept as 0.01:0.01; 0.02:0.02; 0.03:0.03 and 0.04:0.04. To prepare the spraying solution, required proportions of the precursor salts were dissolved in doubly deionized water (30 mL in volume). Few drops of $\mathrm{HCl}$ was added to improve the solubility of $\mathrm{SnCl}_{2}$. The solution was stirred thoroughly using a magnetic stirrer for 30 minutes and sprayed on glass substrates maintained at $400{ }^{\circ} \mathrm{C}$, with the help of compressed air at a flow rate of $6 \mathrm{~mL} / \mathrm{min}$. The thickness of the films was calculated using a stylus type profilometer (SJ-301). X-ray diffraction patterns and SEM images were obtained using $\mathrm{X}$ ray diffractometer (PANalytical-PW 340/60 X'Pert PRO), scanning electron microscope (HITACHI S$3000 \mathrm{H})$, respectively. Optical and electrical studies were performed using UV-Vis-NIR double beam spectrophotometer (LAMBDA-35) and two point probe setup, respectively.

\section{Results and discussion}

Fig. 1 shows the XRD patterns of $\mathrm{Sn}_{2} \mathrm{~S}_{3}$ thin films prepared with different $\mathrm{S}: \mathrm{Sn}$ molar concentrations.

It is seen that all the films exhibit a single peak at $2 \theta$ value approximately equal to $31.705^{\circ}$ assigned to the $\left(\begin{array}{lll}2 & 1 & 1\end{array}\right)$ plane corresponding to orthorhombic $\mathrm{Sn}_{2} \mathrm{~S}_{3}$ (JCPDS Card No. 75-2183). It is also observed that the peak intensity of the $\left(\begin{array}{lll}2 & 1 & 1\end{array}\right)$ plane is maximum for the film coated with the spraying solution having $\mathrm{S}: \mathrm{Sn}$ molar concentration equal to 0.02:0.02, confirming its improved crystallinity. The growth along the $\left(\begin{array}{lll}2 & 1 & 1\end{array}\right)$ plane observed here exactly matches with the results reported by Khadraoui et al. [3] for $\mathrm{Sn}_{2} \mathrm{~S}_{3}$ thin films prepared by spray pyrolysis technique. The lattice

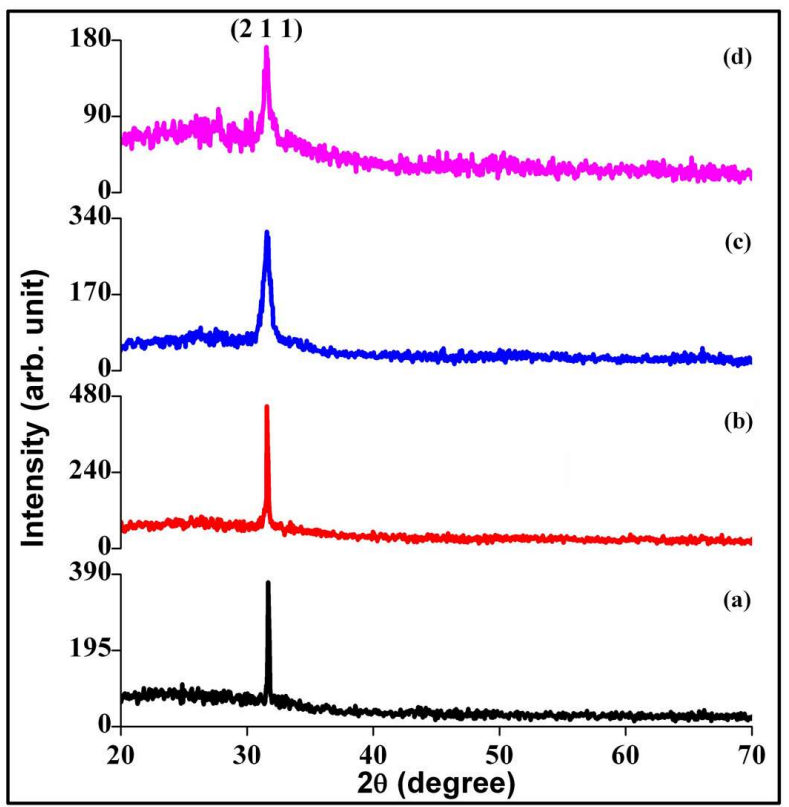

Fig. 1. XRD patterns of $\mathrm{Sn}_{2} \mathrm{~S}_{3}$ thin films prepared with (a) 0.01:0.01, (b) 0.02:0.02, (c) 0.03:0.03 and (d) 0.04:0.04 S:Sn precursor molar concentrations.

parameters of the $\mathrm{Sn}_{2} \mathrm{~S}_{3}$ films were calculated using the relation [13]:

$$
\frac{1}{d^{2}}=\frac{h^{2}}{a^{2}}+\frac{k^{2}}{b^{2}}+\frac{l^{2}}{c^{2}}
$$

and the values are compiled in Table 1. It is observed that the lattice parameters increase when the molar concentration of sulfur and tin (S:Sn) in the starting solution increases. This increase in volume of the unit cell infers that the band gap values of the $\mathrm{Sn}_{2} \mathrm{~S}_{3}$ films should exhibit a red shift which was justified from the Tauc's plots (Fig. 4). The increased d-spacing values observed with the increase in S:Sn precursor molar concentration also supports for the lattice expansion.

The crystallite size (D) of the films was calculated using the Scherrer formula [14]:

$$
D=\frac{0.9 \lambda}{\beta \cos \theta}
$$

where $\lambda$ is the wavelength of the $\mathrm{X}$-ray used (1.5406 $\AA$ ), $\beta$ is the full-width at half maximum of the strongest peak ( $\left(\begin{array}{lll}2 & 1 & 1\end{array}\right)$ in this case) and $\theta$ is the Bragg angle. The calculated D values of the films 
Table 1. Thickness, structural parameters and electrical resistivity values of $\mathrm{Sn}_{2} \mathrm{~S}_{3}$ thin films prepared from solutions having different $\mathrm{S}: \mathrm{Sn}$ precursor molar concentrations.

\begin{tabular}{|c|c|c|c|c|c|c|c|c|c|}
\hline \multirow{2}{*}{$\begin{array}{c}\text { S:Sn precursor } \\
\text { molar concentration }\end{array}$} & \multirow{2}{*}{$\begin{array}{l}\text { Thickness } \\
\mathrm{t}[\mathrm{nm}]\end{array}$} & \multirow{2}{*}{$\begin{array}{c}\mathrm{d}_{(211)} \\
{[\AA]}\end{array}$} & \multirow{2}{*}{$\begin{array}{c}\mathrm{D} \\
{[\mathrm{nm}]}\end{array}$} & \multirow[t]{2}{*}{$\varepsilon \times 10^{-3}$} & \multirow{2}{*}{$\begin{array}{l}\delta \times 10^{-14} \\
{\left[\text { lines } / \mathrm{m}^{2}\right]}\end{array}$} & \multicolumn{3}{|c|}{ Lattice parameters $[\AA]$} & \multirow{2}{*}{$\begin{array}{c}\rho \\
{[\Omega \cdot \mathrm{cm}]}\end{array}$} \\
\hline & & & & & & $\mathrm{a}$ & $\mathrm{b}$ & $\mathrm{c}$ & \\
\hline 0.01:0.01 & 90 & 2.8099 & 45.9 & 0.755 & 4.7489 & 15.554 & 5.620 & 5.659 & 0.238 \\
\hline $0.02: 0.02$ & 122 & 2.8115 & 56 & 0.619 & 3.1931 & 15.563 & 5.623 & 5.662 & 0.359 \\
\hline 0.03:0.03 & 176 & 2.8136 & 42 & 0.826 & 5.6773 & 15.575 & 5.627 & 5.666 & 1.095 \\
\hline 0.04:0.04 & 206 & 2.8231 & 35.6 & 1.032 & 8.8709 & 15.627 & 5.646 & 5.685 & 6.38 \\
\hline
\end{tabular}

are given in Table 1. The highest value of crystallite size obtained for the $\mathrm{Sn}_{2} \mathrm{~S}_{3}$ film coated with $\mathrm{S}: \mathrm{Sn}$ precursor molar concentration equal to 0.02:0.02 confirms its improved crystallinity. The strain $(\varepsilon)$ and dislocation density $(\delta)$ values of the films were calculated using the formulae [15]:

$$
\begin{gathered}
\varepsilon=\frac{\beta \cos \theta}{4} \\
\delta=\frac{1}{D^{2}}
\end{gathered}
$$

The calculated $\varepsilon$ and $\delta$ values are presented in Table 1. The minimum values of strain and dislocation density obtained for the film with $\mathrm{S}: \mathrm{Sn}=0.02: 0.02$ might be the reason for the increased crystallite size observed for this film.

Fig. 2 shows the SEM images of $\mathrm{Sn}_{2} \mathrm{~S}_{3}$ thin films prepared from precursor solutions having different $\mathrm{S}: \mathrm{Sn}$ molar concentrations.

The surface is composed of grains with flake like structures for the film with $\mathrm{S}: \mathrm{Sn}$ equal to 0.01:0.01 (Fig. 2a). With an increase in precursor molar concentration, the surface gets modified with needle shaped grains for the film with S:Sn molar concentration equal to 0.02:0.02 (Fig. 2b). No needled grains are visible for the film coated with $\mathrm{S}: \mathrm{Sn}$ molar concentration 0.03:0.03 (Fig. 2c). The grains appear to be spherical with reduced size. The surface appears to be cloudy with no grains evinced for the film coated with S:Sn precursor molar concentration equal to 0.04:0.04 (Fig. 2d). The uniformity and homogeneous nature observed for the films coated with low precursor molar concentrations (0.01:0.01 and 0.02:0.02) confirmed their improved crystallinity.

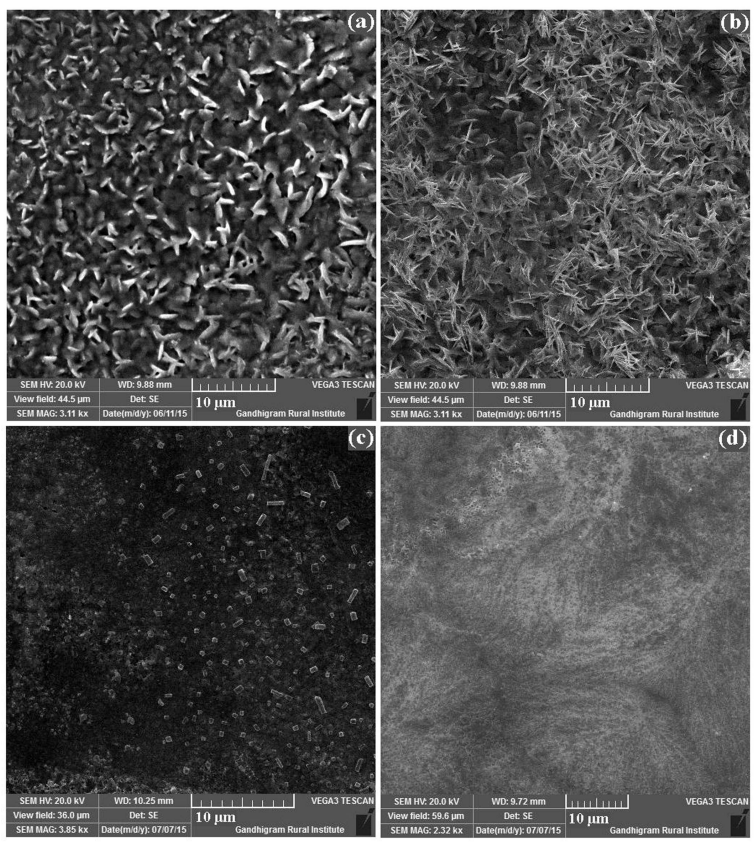

Fig. 2. SEM images of $\mathrm{Sn}_{2} \mathrm{~S}_{3}$ thin films prepared with (a) $0.01: 0.01$, (b) $0.02: 0.02$, (c) 0.03:0.03 and (d) 0.04:0.04 S:Sn precursor molar concentrations.

Fig. 3 shows the transmission spectra of the as deposited $\mathrm{Sn}_{2} \mathrm{~S}_{3}$ thin films.

The film transparency decreases gradually as the molar concentration of sulfur and tin (S:Sn) in the starting solution increases. The reduced transparency observed with the increase in precursor molar concentration might be due to the increased thickness obtained (Table 1). The increase in the film thickness causes a decline in transmission due to the surface scattering mechanism and roughness [16]. It is also observed from Fig. 3 that the absorption edge shift towards higher wavelength side as the $\mathrm{S}: \mathrm{Sn}$ precursor molar concentration 


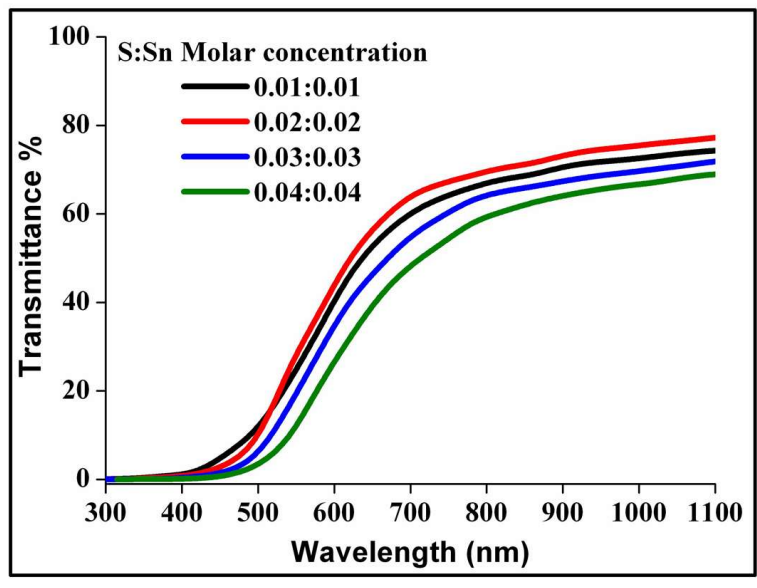

Fig. 3. Transmittance spectra of $\mathrm{Sn}_{2} \mathrm{~S}_{3}$ thin films.

increases, indicating a decrease in the optical band gaps values. The band gap of the films are estimated from Tauc's relation connecting the absorption coefficient $(\alpha)$ and the photon energy (hv) as:

$$
\alpha h v=A\left(h v-E_{g}\right)^{n}
$$

where $\mathrm{A}$ is an energy independent constant and the exponent ' $n$ ' depends on the type of transition $(n=1 / 2,2,3 / 2$ and 3 for allowed direct, allowed indirect, forbidden direct and forbidden indirect transitions, respectively) [17]. The direct band gap values are determined from the Tauc's plots (Fig. 4) by extrapolating the straight line portion to the energy axis.

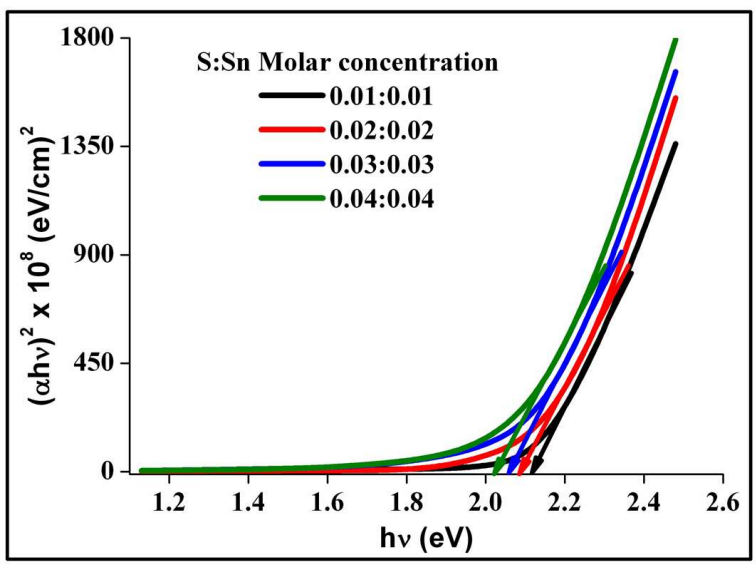

Fig. 4. Tauc's plots of $\mathrm{Sn}_{2} \mathrm{~S}_{3}$ thin films.

The band gap values of the $\mathrm{Sn}_{2} \mathrm{~S}_{3}$ films with 0.01:0.01, 0.02:0.02, 0.03:0.03 and 0.04:0.04 S:Sn precursor molar concentrations were found to be equal to $2.12 \mathrm{eV}, 2.08 \mathrm{eV}, 2.06 \mathrm{eV}$ and $2.02 \mathrm{eV}$, respectively. It is observed that the optical band gap decreases as the molar concentration of sulfur and tin $(\mathrm{S}: \mathrm{Sn})$ in the precursor solution increases and this red shift in the band gap values may be due to the quantum size effect [18]. The reduced band gaps with increasing precursor molar concentration may also be caused by deviation out of the $S: S n=1$ stoichiometry, which induces lattice faults in the films [19].

The electrical resistivity values of $\mathrm{Sn}_{2} \mathrm{~S}_{3}$ films prepared from precursor solutions having different $\mathrm{S}:$ Sn molar concentrations are listed in Table 1. It is observed that the resistivity values increase when the molar concentration of sulfur and tin $(\mathrm{S}: \mathrm{Sn})$ in the starting solution increases. The increase in resistivity with increasing precursor molar concentration might be due to the decreased grain size or increased lattice defects [20].

Fig. 5 shows the room temperature PL spectra of $\mathrm{Sn}_{2} \mathrm{~S}_{3}$ thin films prepared from precursor solutions having $\mathrm{S}: \mathrm{Sn}$ molar concentrations equal to $0.01: 0.01$ and $0.02: 0.02$, excited at wavelength $\lambda=540 \mathrm{~nm}$.

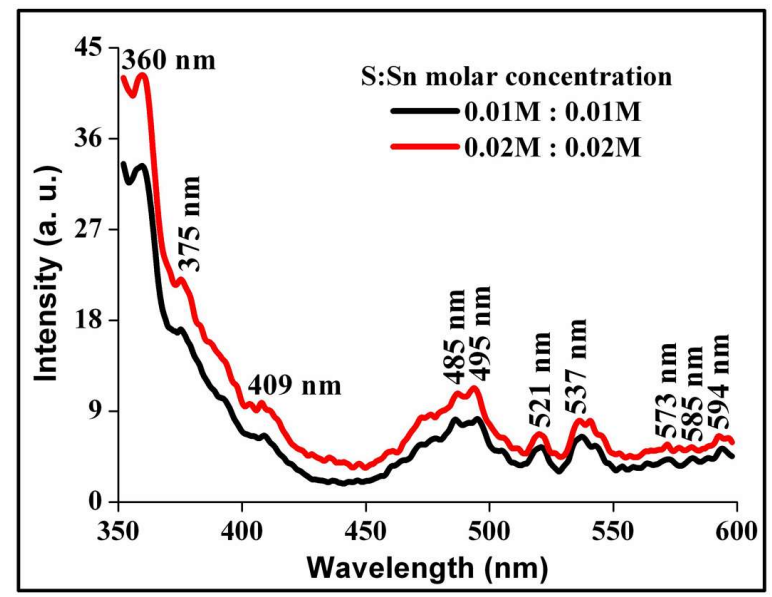

Fig. 5. PL spectra of $\mathrm{Sn}_{2} \mathrm{~S}_{3}$ thin films coated with 0.01:0.01 and 0.02:0.02 S:Sn precursor molar concentrations.

The low intensity luminescence peaks observed in the films might be attributed to inter-impurity transitions and larger stoichiometric deviations 
in the films. The peaks at $360 \mathrm{~nm}$ and $375 \mathrm{~nm}$ may be attributed to higher level excitonic emissions related to quantum confinement [21]. The peak at $409 \mathrm{~nm}$ may result from the recombination between the sulfur-vacancy-related donor and the valence band [22]. The peaks at $485 \mathrm{~nm}$ and $495 \mathrm{~nm}$ may be ascribed to defect centers attributed to excitonic transitions which are size dependent and excitation wavelength-independent in certain wavelength range. $\mathrm{S}$ vacancy states are most likely responsible for the peaks at $360 \mathrm{~nm}, 485 \mathrm{~nm}$ and $495 \mathrm{~nm}$, respectively. The $\mathrm{S}$ vacancies act as deep level traps for electrons and they can exothermically extract electrons from the valence band. This is in accordance with the results reported by Sivaraman et al. [23] for Mg-doped CdS thin films. The emission peak at $521 \mathrm{~nm}$ may be due to the presence of electron hole recombination via trap states or imperfection sites [24]. The peak at $537 \mathrm{~nm}$ can be attributed to the presence of sulfur species on the surface of the sample [25]. Vigil et al. [27] observed a similar peak at $544 \mathrm{~nm}$ which they attributed to sulfur interstitial acceptors $\mathrm{I}_{\mathrm{s}}^{-}$compensated by a close ionized donor center. The PL peak observed at $573 \mathrm{~nm}$ corresponds to radiative recombination involving shallow levels in the band gap due to native impurities. The emission peaks at $585 \mathrm{~nm}$ and $594 \mathrm{~nm}$ are due to deexcitation of electron via the surface/defect states present in the films. The electrons, after excitation across the band edge, are transferred nonradiatively to the surface states extending into the band gap region [27]. The peak observed at $594 \mathrm{~nm}$ is discussed in the literature as a donor-acceptor pair (DAP) [28].

\section{Conclusion}

Spray pyrolysis technique has been successfully employed to fabricate $\mathrm{Sn}_{2} \mathrm{~S}_{3}$ thin films from precursor solutions having different $\mathrm{S}$ :Sn molar concentrations. From the structural studies, it has been found that the film coated with S:Sn molar concentration equal to 0.02:0.02 had better crystalline quality. SEM images confirmed that the precursor molar concentration altered the film morphology to a large extent and the film coated with
0.02:0.02 S:Sn molar concentration had better surface morphology. Optical band gap was red shifted with an increase in precursor molar concentration which may be attributed to quantum size effect. Film resistivity increased with an increase in precursor molar concentration. From the obtained results it can be concluded that 0.02:0.02 S:Sn molar concentration is the optimized concentration for preparing $\mathrm{Sn}_{2} \mathrm{~S}_{3}$ films with better physical properties.

\section{Acknowledgements}

The authors are thankful to the Head, Department of Chemistry and Mr. Gowtham, Gandhigram Rural Institute, Dindugal for the SEM and EDX measurements.

\section{References}

[1] Jiang T., Ozin G.A., J. Mater. Chem., 8 (1998), 1099.

[2] Radot M.B., DAy P., Adv. Inorg. Chem. Radiochem. 10 (1967), 247.

[3] Khadraoui M., Benramdane N., Mathieu C., Bouzidi A., Miloua R., Kebbab Z., Solid State Commun., 150 (2009), 297.

[4] Lofersky J.J., Appl. Phys., 27 (1956), 77.

[5] Khelia C., Boubakar K., Ben Nasrallah T., Amlouk M., Belgaum S., SAadallah F., Yocoubi N., J. Crys. Growth, 311 (2009), 1032.

[6] Yue G.H., Wang W., Wang L.S., Wang X., Yan P.X., Chen Y., Peng D.L., J. Alloy. Compd., 474 (2010), 445

[7] Khomane A.S., J. Alloy. Compd., 506 (2010), 849.

[8] Chate P.A., Hankare P.P., Sathe D.J., J. Alloy. Compd., 505 (2010), 140.

[9] Sehlat R., Armstrong N.R., Parkinson B.A., Pettenkofer C., Jaegermann W., Surf. Sci., 385 (1997), 1.

[10] Ghosh B., Das M., Banerjee P., Das S., Appl. Surf. Sci., 254 (2008), 6436.

[11] Salah H., Bouzouita H., Rezig B., Thin Solid Films, 480 - 481 (2005), 439.

[12] Lopez S., Granades S., Ortiz A., Semicond. Sci. Technol., 11 (1996), 433.

[13] Manjula N., Usharani K., Abalu R., NAGarethinam V.S., Int. J. Chem. Tech. Res., 6 (2014), 705 .

[14] Usharani K., Balu A.R., Acta Metall. Sin., 28 (2015) 64

[15] Narasimman V., Nagarethinam V.S., BalU A.R., Suganya M., Anbarasi M., Usharani K., Int. J. Appl. Res. Eng. Sci., 1 (2014), 7.

[16] Al-Douri Y., Khasawneh Q., KiWan S., HaShim U., ABD HAMID S.B., RESHAK A.H., Bouhemadou A., Ameri M., Khenata R., Energ. Convers. Mange., 82 (2014), 238. 
[17] Rajashree C., Balu A.R., Nagarethinam V.S., Surf. Eng., 31 (2015), 316.

[18] Syed Basheer Ahamed M.G., Nagarethinam V.S., Balu A.R., Thayumanavan A., Murali K.R., Sanjeeviraja C., Jayachndran M., Cryst. Res. Technol., 45 (2010), 421.

[19] Chu J., Jin Z., Wang W., LiU H., Wang D., YAng J., Hong Z., J. Alloy. Compd., 517 (2012), 54.

[20] Syed Basheer Ahamed M.G., Balu A.R., NAgarethinam V.S., Thayumanavan A., Murali K.R., Sanjeeviraja C., Jayachndran M., Cryst. Res. Technol., 45 (2010), 387.

[21] Anbarasi M., Sivaraman T., Nagarethinam V.S., Balu A.R., Int. J. Chem. Phys. Sci., 3 (2014), 1.

[22] Chalana S.R., Vinodkumar R., Navas I., GaneSan V., Mahadevan Pillai V.P., J. Lumin., 132 (2012), 944.
[23] Sivaraman T., Balu A.R., Nagarethinam V.S., Mat. Sci. Semicond. Proc., 27 (2014), 915.

[24] Chaura S., Chaura N.B., Pandey R.K., Physica E, 28 (2005), 439.

[25] Ye C.H., Fang X.S., Li G.H., Zhang L.D., Appl. Phys. Lett., 85 (2004), 3035.

[26] Ehrlich W., Gumlich H.E., Tschierse D., J. Crys. Growth, 72 (1985), 37.

[27] Vigil O., Riech I., Garcia-Rocha M., ZelayaAngel O., J. Vac. Sci. Technol. A, 15 (1997), 2282.

[28] Mochizuki K., Satoh M., Igaki K., Jpn. J. Appl. Phys., 22 (1983), 1414.

Received 2015-10-30 Accepted 2016-01-15 